\title{
Ondas Eletromagnéticas no Espectro Raio-X num Contexto da Ciência, Tecnologia e Sociedade
}

\section{Electromagnetic Waves in X-Ray Spectrum in a Context Science, Technology and Society}

Heloiza Salvador ${ }^{1}$, Patricia de Oliveira ${ }^{2}$, Marlon de Oliveira Alves da Silva ${ }^{3}$, Mateus das Neves Gomes ${ }^{4}$

\section{RESUMO}

Os raios-X são produzidos por ondas eletromagnéticas no espectro não visível, sendo essas descritas por equações vetoriais. O primeiro estudo publicado sobre o Raio-X foi realizado por Kienböck em 1907. Em seu trabalho ele propôs a classificação qualitativa dos raios- $X$, com relação a sua penetrabilidade no tecido humano, ou seja, a qualidade dos feixes liberados pela máquina. Desde sua invenção, as máquinas passaram e passam por mudanças constantes, tanto quanto na produção e emissão dos raios até na entrega dos resultados. Diante desse contexto, o presente artigo aborda o princípio de funcionamento de uma máquina de Raio-X, do ponto de vista físico e matemático sob o viés da Ciência, Tecnologia e Sociedade (CTS). Desse modo, estudou-se a evolução de tal aparelho e seus impactos sociais através da mudança de paradigma apresentado por Thomas Kuhn. As mudanças de paradigmas são associadas pelas transformações ocorridas na tentativa de aperfeiçoar o Raio-X. Durante esse processo que perdura até os dias atuais, muitos paradigmas foram colocados em prova, mas não necessariamente refutados, no entanto, fazem parte da evolução e sem eles, talvez os avanços não seriam tão significativos. A mudança do paradigma, tem corroborado para o aperfeiçoamento dos resultados e atenuando os impactos socioambientais.

Palavras-chave: Ciência, Tecnologia e Sociedade. Raio-X. Paradigma.

\section{ABSTRACT}

X-rays are produced by electromagnetic waves in the non-visible spectrum, and these are described by vector equations. The first study published on the X-ray was made by Kienböck in 1907. In his work he proposed the qualitative classification of X-rays, in relation to their penetrability in human tissue, that is, the quality of the beams released by the machine. Since its invention, the machines have passed and undergo constant changes, as much as in the production and emission of the rays until the delivery of the results. In this context, the article addresses the operating principle of an X-ray machine from a physical and mathematical point of view under the Science, Technology and Society (CTS) bias. In this way, the evolution of this apparatus and its social impacts through the paradigm shift presented by Thomas Kuhn was studied. The paradigm changes are associated with the transformations that have occurred in the attempt to perfect the X-ray. During this process that lasts until the present day, many paradigms have been put to the test, but not necessarily refuted, nevertheless, they are part of the evolution and without them, perhaps the advances would not be so significant. The paradigm shift has corroborated the improvement of results and mitigation of social and environmental impacts.

Keywords: Science, Technology and Society. X-ray. Paradigm.
${ }^{1}$ Licencianda em Física, Instituto Federal do Paraná - Campus Paranaguá.

E-mail:

heloizasalvador@gmail.com.

2Mestranda em Ciência, Tecnologia e Sociedade, Instituto Federal do Paraná - Campus Paranaguá

${ }^{3}$ Mestrando em Ciência, Tecnologia e Sociedade, Instituto Federal do Paraná - Campus Paranaguá

${ }^{4}$ Prof. Dr. Mateus das Neves Gomes, Instituto Federal do Paraná - Campus Paranaguá. 


\section{INTRODUÇÄO}

O desenvolvimento da física atômica possui relevância para todas as grandes áreas da ciência, em especial, tratada no presente artigo, a medicina. Durante toda a evolução da física atômica, muitas mudanças de paradigmas ocorreram, do que era extrema verdade à mais falsa falácia.

No ano de 1895 o físico alemão Wilhelm Conrad Röntgen, que além de professor foi um grande pesquisador na área do eletromagnetismo, mais precisamente com o estudo de raios catódicos, contribuiu com uma grande descoberta para a sociedade, os raios- $x$ (PEREIRA, 2012). Tal descoberta, Ihe valeu o primeiro prêmio Nobel da Física, no ano de 1901.

O descobrimento desses raios invisíveis, nomeados de " $X$-strahlen" (raio- $\mathrm{X}$ ) - "X" por ser de natureza desconhecida - não revolucionaram apenas o campo da física atômica, mas outras áreas da ciência (PEREIRA, 2012). A medicina, por exemplo, obteve grandes avanços a partir dos raios- $x$, onde foram desenvolvidas diferentes aplicações nas mais variadas especialidades. Uma das aplicações é a máquina de Raio- $X$, objeto de discussão neste trabalho.

A primeira radiografia registrada por Röntgen foi da mão de sua esposa, a radiografia foi impressa numa placa de fotografia pelos processos convencionais de antigamente. Essa placa foi exposta por trinta minutos, podendo assim comprovar toda teoria e invento realizado por Röntgen (PEREIRA, 2012).

Desde a sua invenção o aparelho do Raio-X passou e passa por diversas mudanças, seja para melhorar a qualidade dos feixes emitidos; para inovar a maneira como a placa de radiografia é impressa e, com grande destaque, o objetivo de aperfeiçoar os equipamentos de segurança para que os raios não ofereçam qualquer tipo de risco a saúde do paciente e do médico.

Logo, seria indevido dar toda a credibilidade da descoberta dos raios- $x$ somente a Röntgen, por mais que ele tenha sido o descobridor, muitos cientistas antes dele desenvolveram estudos que permitiram a ele a explicação desse fenômeno. Outros cientistas contribuíram para o seu aperfeiçoamento, o seu estudo e as suas aplicações; muitos estudaram as possíveis maneiras de entregar os resultados aos pacientes sem que a placa radiográfica tenha grande impacto no ambiente, dentre outros.

Diante deste contexto, o presente artigo tem o objetivo de apresentar o princípio do funcionamento de uma máquina de Raio-X, utilizando o ponto de vista físico e matemático 
sob o viés da Ciência, Tecnologia e Sociedade (CTS), a qual é uma área de pesquisa de caráter interdisciplinar que constitui uma relação entre o conhecimento científico e tecnológico (BAZZO, 2013), nos quais são destacados os seus aspectos sociais, promovendo uma visão não tradicional da atividade científica.

Sendo assim, a discussão do presente artigo está em identificar a mudança do paradigma, pautando-se na obra escrita por Thomas Samuel Kuhn. A obra foi traduzida para a versão na língua portuguesa em 1970 - A Estrutura das Revoluções Científicas, busca realizar uma analogia com o paradigma na obra, e apresenta a mudança do paradigma, estruturando assim a proposta com o campo da ciência, tecnologia e sociedade. Um paradigma é aquilo que os membros de uma comunidade científica partilham, e uma comunidade consiste em pessoas que partilham de um mesmo paradigma (KUHN, 1998). Deste modo, a descoberta dos raios-x e da máquina de Raio-X é fruto de um trabalho em comunidade, dos que antecederam os estudos aos que aperfeiçoaram e ajudaram a explicar a descoberta.

\section{O DESENVOLVIMENTO DO APARELHO DE RAIO-X}

Ao longo de muito tempo se desconhecia as ondas eletromagnéticas e era um insulto pesquisar sobre isso, no entanto o físico inglês James Clerk Maxwell não se contentou apenas com o estudo experimental de Faraday e decidiu escrever matematicamente tudo o que Faraday havia descoberto apenas experimentalmente. Ao fim de seu estudo, Maxwell conseguiu provas matemáticas da existência das ondas eletromagnéticas, concluindo também que a luz é um tipo de onda eletromagnética.

Numa sala escura, Röntgen colocou um tubo, de vácuo adequado, dentro de uma caixa de cartão preta e, quando forneceu uma energia elétrica de alta tensão, verificou a existência de fluorescência num ecrã com cristais, numa distância que a fluorescência poderia ser vista até a dois metros distante. Ao observar tal fenômeno, ele decidiu colocar diversos objetos que deveriam ser opacos aos raios catódicos - radiação que consiste em feixes de elétrons emitidos por um cátodo num tubo a vácuo -, onde a fluorescência sempre se manifestava (PEREIRA, 2012).

Ao expor diversos materiais de diferentes densidades, Röntgen percebia que a fluorescência permanencia, e ao interpor sua mão neste percurso, verificou a projeção dos ossos de sua mão no ecrã fluorescente (MARTINS, 1998). Nesta projeção ele pode perceber que seus ossos apareciam mais escuros que os tecidos de sua mão, sendo assim, ele foi o primeiro a ter uma visão radioscópica de seus ossos. 
A fim de documentar seu descobrimento, Röntgen fez uma analogia do estudo sobre raios catódicos com o raios-x. Sabendo que os raios catódicos marcavam placas fotográficas, ele tentou usar o mesmo processo para registrar a "sombra" decorrente do raios-x, então ele substituiu o ecrã por uma placa fotográfica. A primeira radiografia registrada foi de sua esposa. Anna Bertha Lugwig, que após a revelação da placa fotográfica por processos convencionais, teve a fotografia dos ossos de sua mão registrada (PEREIRA, 2012).

No processo de aperfeiçoamento da máquina de Raio-X que ocorre até os dias atuais, muitas alterações foram realizadas. A primeira mudança feita foi tanto para proporcionar uma proteção adequada contra a radiação e os choques elétricos, quanto para ter um melhor controle da quantidade e qualidade da radiação produzida. Tal mudança não produzia apenas um feixe de raios-x mais intenso, mas quando necessário, obtinha uma radiação com maior poder de penetração.

Em 1904, a Siemens-Reiniger produziu o primeiro aparelho de Raio-X com um gerador monofásico e retificação de onda completa. Esse tipo de gerador, possibilitou a produção de uma maior quantidade de raios- $x \mathrm{e}$, consequentemente, um tempo menor na duração dos exames (NAVARRO, 2009).

Kienböck publicou o primeiro estudo sobre o Raio-X em 1907, propondo uma identificação qualitativa dos raios-x com relação a qualidade dos feixes (NAVARRO, 2009). A qualidade desses feixes é de total importância para o contraste da radiografia e para a visualização da imagem; quanto mais denso ou mais espesso é o local a ser radiografado, maior há de ser a qualidade do feixe de raios-x a ser utilizado.

No ano de 1911, o engenheiro Coolidge idealizou um tubo de alto vácuo com focalização de feixe, semelhante aos tubos usados hoje, alavancando um grande avanço na qualidade dos feixes e sua reprodutibilidade (NAVARRO, 2009). Outro grande avanço com relação a qualidade dos feixes de raios- $x$, foi o conceito desenvolvido pelo físicomédico Christén, o qual possibilitou um controle quantitativo dessa qualidade.

O conceito da camada semi redutora (CSR), quantidade de material necessária para reduzir a intensidade de um feixe de raios-x à metade, possibilitou especificar de forma quantitativa a qualidade de um feixe, e consequentemente, relacionar a qualidade do feixe adequada para cada tipo de exame.

Até os dias atuais, as máquinas de Raio-X passam por constantes mudanças, seja na qualidade dos feixes de raios-x, seja nos tubos de alto vácuo, na proteção contra a radioatividade, no material em qual a radiografia é impressa e etc. 
No estudo de Röntgen, os raios-x eram produzidos quando os elétrons colidiam com as paredes do tubo evacuado, sendo mostrado que os raios se propagavam em linha reta e tinham um grande poder de penetração. Por muitos anos os cientistas buscaram uma explicação da natureza desses raios, até que se chegou à conclusão de que eram partículas neutras e foi sugerido que podiam ser ondas eletromagnéticas, assim como a luz, com um comprimento na ordem de $10^{-10} \mathrm{~m}$ (NUSSENZVEIG, 1998).

As ondas eletromagnéticas são modeladas a partir das equações de Maxwell que são imersas no cálculo vetorial, a qual é uma área da matemática que se restringe na diferenciação e integração de campos vetoriais, mais frequentemente no $R^{3}$ (STEWART, 2016).

Essa área da matemática é importante para a área da Física e da Engenharia, muito usado para descrever campos eletromagnéticos, vetoriais e mecânica dos fluidos. As equações que descrevem as ondas eletromagnéticas podem ser obtidas a partir do cálculo vetorial e das equações de Maxwell.

Inicialmente, analisa-se as ondas num campo elétrico e posteriormente em um campo magnético. Para o campo elétrico, a lei de Faraday e a lei de Àmpere serão usadas como base para descrever a equação da onda nesse meio.

A lei de Faraday é expressa pela Eq. (1) e a lei de Àmpere pela Eq. (2):

$$
\begin{aligned}
& \Delta \times \vec{E}=-\frac{\partial \vec{B}}{\partial t}, \\
& \Delta \times \vec{B}=\mu \varepsilon \frac{\partial \vec{E}}{\partial t},
\end{aligned}
$$

sendo $\vec{E}$ e $\vec{B}$ os campos elétricos e magnéticos respectivamente; e $\Delta \times$ é o rotacional desses campos.

A partir dessas equações, pode-se definir que a onda se propaga num campo elétrico como expressa a Eq. (3):

$$
\nabla^{2} \vec{E}=\mu \varepsilon \frac{\partial^{2} \vec{E}}{\partial t^{2}}
$$

em que o laplaciano do campo elétrico é igual ao produto das constantes de permissividade do meio pela a derivada parcial do campo em relação ao tempo. 
O mesmo conceito foi usado para expressar a equação da onda num campo magnético, na qual utiliza-se a Eq. (2) para obter a equação da propagação da onda num meio magnético:

$$
\nabla^{2} \vec{B}=\mu \varepsilon \frac{\partial^{2} \vec{B}}{\partial t^{2}}
$$

$\mathrm{Na}$ máquina de Raio- $\mathrm{X}$, as ondas eletromagnéticas propagam no vácuo, como expressa a seguinte relação:

$$
\vec{B}=\frac{1}{C} \hat{u} \times \vec{E},
$$

sendo o campo magnético $\vec{B}$ inversamente proporcional a velocidade da luz e diretamente proporcional ao campo elétrico $\vec{E}$.

3. A CONSTRUÇÃO DE UM PARADIGMA DECORRENTE DA DESCOBERTA E SUAS RELAÇÕES COM A CIÊNCIA, TECNOLOGIA E SOCIEDADE

A abordagem da Ciência, Tecnologia e Sociedade configura uma tríade conceitual que apresenta uma relação entre o conhecimento científico e tecnológico no âmbito social (BAZZO, 2003, p.10). A evolução tecnocientífica se desenvolve imbricada na sociedade em que a ciência e a tecnologia exerce um papel decisivo em sua própria configuração. Logo a área da ciência, tecnologia e sociedade culminam na análise das relações e nas implicações da ciência e tecnologia na sociedade (BAZZO, 2003).

Ainda, a ciência normal produz tijolos para que a pesquisa científica esteja sempre complementando ao crescente acervo do conhecimento científico (KUHN, 2017). Essa concepção é vista como algo cumulativo no desenvolvimento do mundo científico, mas é preciso que se tome cuidado ao lidar com essa concepção, em determinados casos a ciência não é cumulativa, ocorrendo então uma quebra em tal processo.

Nesse sentido, apresentou-se o contexto histórico dos estudos relacionados ao raio-x e a construção do aparelho de raio, o qual trouxe notáveis contribuições para a saúde pública (NAVARRO, 2009). Assim, nota-se a construção de um paradigma através da evolução do conceito do raio-x, conforme afirma Thomas Kuhn: "paradigmas servem como uma linguagem padrão para uma certa comunidade científica" (KUHN, 1998). Desse modo, um paradigma pode ser identificado através das pesquisas do passado que foram reconhecidas e que deixaram fundamentos para as práticas posteriores. 
Em vista disso, a construção do paradigma na abordagem do raio-x é constituída a partir da descoberta do mesmo, levando em consideração o seu aspecto social. De acordo com a teoria de Thomas Kuhn, quando algo novo é descoberto, como por exemplo os raios- $x$, o conhecimento passa a ser entendido de outra maneira. Pode-se dizer que os cientistas, numa analogia em grande escala, antes de uma revolução viviam em um planeta e que após essa revolução eles foram transportados para outro planeta. Segundo Kuhn (1998):

[...] as mudanças de paradigmas realmente levam os cientistas a ver o mundo definido por seus compromissos de pesquisa de uma maneira diferente. Na medida em que seu único acesso a esse mundo dá-se através do que veem e fazem, poderemos ser tentados a dizer que, após uma revolução, os cientistas reagem a um mundo diferente (KUHN, 1998, p. 146).

Quando um grupo de cientistas pesquisa uma área da ciência, neste caso a física, é possível dizer que tal grupo cria uma comunidade científica. De acordo com Kuhn (1998), há escolas na ciência, que estudam o mesmo objeto científico a partir de pontos de vista diferentes (KUHN, 1998).

Essa discordância dos pontos de vistas, gera uma discrepância na comunidade científica, que não costuma durar muito tempo, mas que produz um resultado onde os membros da comunidade vêem a si mesmo e são vistos pelos outros como únicos responsáveis pela perseguição de um conjunto de objetivos.

Pode-se fazer analogia a uma crença, o fato de que essa crença diga que a teoria é verdadeira, ou de que ela é empiricamente adequada, não resulta e nem é resultado pela crença de que a aceitação plena de uma teoria vá ser justificada (FRAASSEN, 2007). Além disso, a saída para o discordante não é dissociar e desagregar os diversos apoios que Röntgen teve durante sua descoberta, mas é sacudir a complicada estrutura que possibilitou a descoberta e a explicação do raio-x (LATOUR, 2011).

Desta forma, logo quando foi anunciada a descoberta de Röntgen, foi cercada por dúvidas e desconfianças. Em uma carta escrita por ele, disse que já esperava por isso e relatou:

Não falei com ninguém sobre meu trabalho. Para a minha esposa, mencionei que eu estava fazendo algo sobre algo o qual as pessoas, quando descobrissem, iriam dizer: "Röntgen provavelmente enlouqueceu" (RÖNTGEN11, 1896 apud MARTINS, 1998, p. 378).

\footnotetext{
${ }^{1}$ Carta de Röntgen para Zehnder, 8 de fevereiro de 1896, transcrita em: NITSKE, Wilhelm Conrad Röntgen, pp. $100-1$.
} 
Segundo Praia e Cachapuz (2005), essas desconfianças podem ser entendidas como um "analfabetismo" científico-tecnológico, não saber utilizar seus conhecimentos para argumentar em situações concretas. Ainda, podem ser tratadas como ciúmes e alegações de que o fenômeno já havia sido descoberto, numa vez que a grande repercussão se deu no meio dos cientistas (MARTINS, 1998).

O custo da discordância aumenta de forma drástica, e o número de cientistas capazes de continuar com tal diminui de forma proporcional. Esse preço pode ser determinado pelo próprio descobridor das quais as informações estejam sendo discutidas. Como membros da comunidade científica, os cientistas discordantes não podem fazer nada a menos do que isso, para que se unam forças e a hipótese seja comprovada ou não (LATOUR, 2011).

Dentre todos os pontos altos dessa descoberta, trata-se aqui como uma das principais, que esse novo paradigma é um meio eficaz de produzir mudanças nos mesmos paradigmas que os orientam, neste caso os raios catódicos.

[...] o empreendimento científico desenvolveu uma técnica particularmente eficiente na produção de surpresas dessa natureza. Se queremos conciliar essa característica da ciência normal com o que afirmamos anteriormente, é preciso que a pesquisa orientada por um paradigma seja um meio particularmente eficaz de induzir a mudanças nesses mesmos paradigmas que a orientam (KUHN, 1998, p. 78).

Desta forma, é válido destacar que muitos paradigmas foram aperfeiçoados, alguns foram derrubados e outros aceitos no meio científico. A descoberta dos raios- $x$ tem como principal nome Wilhelm Conrad Röntgen, mas não se pode esquecer de outros cientistas que colaboraram com essa descoberta, os quais são membros da comunidade científica.

Assim sendo, a acelerada evolução tecnológica do equipamento, corroborou para que houvesse a incorporação deste conhecimento na formação de profissionais da saúde e técnicos das autoridades reguladoras. A construção do paradigma incorpora também a normativa oriunda da Organização Mundial da Saúde (OMS), sugerindo a inclusão de conhecimentos mínimos sobre radiação nos currículos dos cursos vinculados à saúde e para os profissionais da saúde, e a formação base de referência para os profissionais de física médica (NAVARRO, 2009). Nesse contexto, é necessário que existam estratégias para que o debate sobre a ciência e a tecnologia gere insumos voltados ao enfrentamento aos agravos à saúde, que se crie uma interface entre a inovação e a produção com 
assistência. Logo, o Estado com sua função intermediadora, formula e aplica ações que geram desenvolvimento para o aparato social (TENÓRIO; MELLO; VIANA, 2017).

A construção deste paradigma, não abarca somente as considerações científicas, incluem também as bases sociais, cujo o objetivo é primar pelas benécies do uso das radiações, precavendo a ocorrência dos efeitos patológicos e mitigando os efeitos fortuito. Logo, o advento do paradigma preza pela proteção da saúde humana contra os efeitos nocivos das radiações (NAVARRO, 2009).

\section{CONSIDERAÇOES FINAIS}

A descoberta de Röntgen representou um marco na história da ciência, especialmente na área da medicina, ao influenciar uma prática que durante várias décadas, nenhum outro avanço nos conhecimentos científicos o tenha conseguido. Durante muito tempo, toda uma comunidade científica se propôs e se dedicou para que o aparelho de Raio-X fosse cada vez mais eficaz.

Quanto a mudança de paradigma, conclui-se que um paradigma não necessariamente desconstrói outro, mas muitas vezes contribui para sua aceitação e comprovação. A comunidade científica, valida ou invalida esses paradigmas a partir de seus princípios, o que explica, talvez, toda a não aceitação dos raios-x.

Do mesmo modo que alguns membros da comunidade científica não compreenderam e aceitaram os raios- $x$, outros apoiaram na sua reafirmação, tanto para a formulação mais correta e exata deste fenômeno, quanto para a criação de todos os inventos decorrentes, sendo o principal a máquina de Raio-X.

O ponto de vista físico e matemático sob o viés da ciência, tecnologia e sociedade, apresentou a mudança do paradigma na evolução no funcionamento da máquina do Raio$X$, e seus impactos na sociedade. Essas evoluções podem ser consideradas como mudanças de paradigma, e mais especificamente como uma revolução científica. Durante esse processo que perdura até os dias de hoje, muitos paradigmas foram colocados em prova, mas não necessariamente refutados, no entanto, fazem parte da evolução e sem eles, talvez os avanços não seriam tão significativos. Logo a inovação tecnológica, tem demonstrado a mudança do paradigma, melhorando resultados e atenuando impactos sociais e ambientais. 


\section{REFERENCIAS}

BAZZO, W . A. et al. Introdução aos estudos CTS: 0 que é Ciência, Tecnologia e Sociedade? Cadernos de Ibero-América, Editora OEI, 2003. Disponível em: www.oei.es/historico/salactsi/Livro_CTS_OEl.pdf. Acesso em: 02 Ago. 2018

FRAASSEN, B. C. V. A imagem científica. São Paulo: Editora UNESP, 2007.

KUHN, T. S. A Ciência Normal como Resolução de Quebra-Cabeças. In: A estrutura das revoluções científicas. São Paulo: Editora Perspectiva S. A.,1998, p. 57-67.

A Anomalia e a Emergência das Descobertas Científicas. In: A estrutura das revoluções científicas. São Paulo: Editora Perspectiva S. A.,1998, p. 77-93.

As Revoluções como mudanças de concepção de mundo. In: A estrutura das revoluções científicas. São Paulo: Editora Perspectiva S. A.,1998, p. 145-173.

O caminho desde A estrutura: ensaios filosóficos. In: Reconcebendo as revoluções científicas. São Paulo: Editora Unesp, 2017, p. 23-31.

LATOUR, B. Ciência em ação: como seguir cientistas e engenheiros sociedade afora - vol 1. 4 ed. São Paulo: Editora UNESP, 2011.

MARTINS, R. A. A descoberta dos Raios-X: o primeiro comunicado de Röntgen. Revista Brasileira de Ensino de Física, São Paulo, v. 20, dez. 1998.

NAVARRO, M. V. T. Evolução tecnológica do radiodiagnóstico. In: Risco, radiodiagnóstico e vigilância sanitária. Salvador: EDUFBA, 2009, p. 31-36.

O Radiodiagnóstico na Saúde Pública. In: Risco, radiodiagnóstico e vigilância sanitária. Salvador: EDUFBA, 2009, p. 25-30.

Identificação e controle de riscos em radiodiagnóstico. In: Risco, radiodiagnóstico e vigilância sanitária. Salvador: EDUFBA, 2009, p. 49-76.

NUSSENZVEIG, H. M. Curso de Física básica - vol 4.1 ed. São Paulo: Editora Blucher, 1998.

PEREIRA, A. M. R. Estudo do impacto da descoberta dos Raios-X e das suas aplicações médicas em Portugal. 2012. Dissertação (Mestrado em Química) - Faculdade de Ciências, Universidade de Lisboa, Lisboa.

PRAIA, J.; CACHAPUZ, A. Ciência-Tecnologia-Sociedade: um compromisso ético. Revista CTS. Portugal, v. 2, p. 173-194, dez. 2005.

STEWART, J. Cálculo: volume 2. 8 ed. São Paulo: Cengage Learning, 2016.

TENÓRIO, M., MELLO, G. A., VIANA, A. L. Políticas de fomento à ciência, tecnologia e inovação no Brasil e o lugar da pesquisa clínica. Rio de Janeiro, 2017. 